\title{
Os cadernos de Anita Malfatti no IEB
}

\author{
[ The notebooks of Anita Malfatti at IEB
}

\section{Roberta Valin ${ }^{\mathrm{I}}$}

\section{Carlos Pires ${ }^{2}$}

RESUMO - Este artigo pretende apresentar uma investigação realizada no arquivo de Anita Malfatti, situado no Instituto de Estudos Brasileiros da Universidade de São Paulo, que teve como centro os cadernos que a artista produziu ao longo de sua vida. Esses cadernos, feitos com diferentes propósitos e em contextos distintos, são reveladores tanto da trajetória da artista, quanto da sua atuação no campo artístico paulista. São, ainda, preciosos materiais para compreender a própria constituição desse campo ao longo da primeira metade do século XX. • PALAVRAS-CHAVE - Anita Malfatti; caderno de artista; arte brasileira; Modernismo brasileiro. ABSTRACT
- This article aims to present an investigation of Anita Malfatti's archive, located at the Institute of Brazilian Studies of the University of São Paulo, focusing on sketchbooks and notebooks that the artist maintained throughout her life. Those notebooks and sketchbooks, which were created for different purposes and in different contexts, reveal both Anita's trajectory and her role in the artistic field of São Paulo. Moreover, they are important materials for understanding how that artistic field was established throughout the first half of the 2oth century. - KEYWORDS - Anita Malfatti; artist's notebook; Brazilian art; Brazilian Modernism.

Recebido em 6 de julho de 2018

Aprovado em 29 de outubro de 2018

VALIN, Roberta; PIRES, Carlos. Os cadernos de Anita Malfatti no IEB. Revista do Instituto de Estudos Brasileiros, Brasil, n. 7I, p. 325-337, dez. 2018.

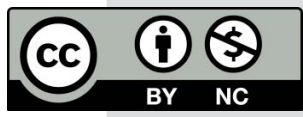

DOI: http://dx.doi.org/Io.II606/issn.23I6-90IX.voi7Ip325-337

I Universidade Federal do Amazonas (UFAM, Manaus, AM, Brasil).

2 Universidade de São Paulo (USP, São Paulo, SP, Brasil). 
Anita Malfatti (I889-I964) carrega junto ao seu nome o legado do pioneirismo da arte moderna brasileira. $\mathrm{O}$ ano de 2017 celebrou o centenário de sua emblemática "Exposição de pintura moderna”, ocorrida em I9I7 na capital paulista - um momento inaugural da arte moderna no contexto brasileiro. Com essa exposição, entre pinturas e desenhos produzidos em grande parte na temporada de estudos nos Estados Unidos entre os anos de I9I4 e I9I6, Anita Malfatti logrou reconhecimento como a introdutora das linguagens de vanguarda no Brasil. E no posto de protagonista, ainda que oscilando em alguns momentos, fez da experiência brasileira, no que tange ao modernismo, um caso atípico no cenário internacional (SIMIONI, 20I7, p. I2).

Essa é a Anita Malfatti que conhecemos, que nos chega hoje ainda tão viva e celebrada. Mesmo que importantes e necessárias revisões sobre sua vida e obra tenham ocorrido nas últimas décadas - haja vista trabalhos de Marta Rossetti Batista, Tadeu Chiarelli, Ana Paula Cavalcanti Simioni, Renata Cardoso, Morgana Viana -, ainda há muito o que se revelar sobre a artista para além da imagem cristalizada e enrijecida apresentada pela historiografia canônica do modernismo brasileiro. Muito sobre sua trajetória artística, atuação no campo artístico, seja como artista ou como educadora, sobre a forma como compreendeu e vivenciou a arte, a pintura, o desenho e sobre suas referências artísticas se mantém nebuloso.

Existe, no entanto, uma Anita Malfatti pouco conhecida, desconhecida mesmo, mas que se mantém viva em seu arquivo pessoal. "Voltar-se para essa(s) Anita(s) no limite de seu arquivo pode ser um caminho possível para um olhar crítico e atualizado para sua vida e obra” (VALIN, 20I7); um percurso que permite perfurar "um conjunto de camadas discursivas acumuladas em um século de sua presença nos meios artísticos brasileiros" (SIMIONI, 20I7, p. I2).

Desde que chegou ao Instituto de Estudos Brasileiros da Universidade de São Paulo em I989, doado pela família da artista sob a mediação da então pesquisadora do Instituto e sua principal biógrafa, Marta Rossetti Batista, seu arquivo pessoal encontra-se em dois setores: Arquivo e Coleção de Artes Visuais. São ao todo I.06o documentos salvaguardados no Arquivo e outras I04 obras na Coleção de Artes Visuais.

A riqueza de seu arquivo é notável, seja do ponto de vista da variedade da documentação, seja pelo teor memorialístico que alude à sua vida e à sua produção/ criação artística durante quase cinco décadas. Seu valor também está associado ao 
fato de que o conjunto documental, direta ou indiretamente, desvela informações e propõe questões sobre o campo artístico e intelectual de São Paulo e do exterior na primeira metade do século XX, particularmente da Alemanha (I9IO-I9I3), Estados Unidos (I9I4-I9I6) e França (I923-I928), países que a acolheram para temporadas de estudos artísticos.

Algumas das vias de acesso a essas Anitas, escondidas pela artista da polêmica com Monteiro Lobato iniciadora do modernismo no Brasil, estão presentes no arquivo. Anita Malfatti, com efeito, produziu e acumulou ao longo de sua vida cadernos para diversos fins, utilizando como técnicas a escrita, o desenho e, ainda, recortes e colagens. Não é raro ver essas técnicas juntas em um mesmo caderno, o que, de alguma forma, aponta para seus interesses e objetivos. O principal, ao que tudo indica, é servir como um suporte sempre à mão para registros rápidos, estudos ou reflexões gráficas e escriturais, para, assim, poder usá-los como dispositivos de rememoração, seja para seu próprio processo de criação, seja para a sua vida. Servem, portanto, de instrumentos privilegiados para compreender as diversas formas como ela forja uma imagem de si. Esse material, justamente por essas características, permite acessar, como dito, de fato diversas faces da artista.

Podemos chamar de cadernos de desenho os I7 cadernos sob a guarda da Coleção de Artes Visuais do IEB/USP que apresentam como técnica de registro dominante o desenho ${ }^{3}$. A esses foi agregado recentemente mais um que estava desaparecido provavelmente desde os anos de I9804, um raro documento da década de I9IO5, feito possivelmente na primeira metade dessa mesma década e que possui um registro escrito, em forma de diário, relacionado à sua primeira exposição individual realizada na cidade de São Paulo em I9I4.

Já envelhecidos pelo tempo, alguns no formato brochura e outros em espiral, e apresentando diversos tamanhos, formatos e números de páginas, nos cadernos das décadas seguintes coexistem, ao lado dos desenhos e colagens, poucas e esparsas

3 Ao todo são I7 cadernos de desenho salvaguardados no setor de Coleção de Artes Visuais. Para uma pesquisa inicial, acessar o Catálogo Eletrônico (IEB, s. d.).

4 Em pesquisa realizada no arquivo de Emilie Chamie, recentemente incorporado ao Instituto de Estudos Brasileiros (IEB), encontramos esse diário junto a outros materiais da artista. Entendemos, então, o que parece ter acontecido: Emilie Chamie foi a responsável pelo projeto gráfico de um livro que apresentou uma versão parcial do estudo de Marta Rossetti Batista (I985) sobre a pintora em meados da década de I980. Provavelmente, nesse momento, Emilie Chamie pegou esse material para usar no projeto gráfico, usou, pois de fato muitas imagens desse material estão no livro de I985, e colocou em um envelope pardo direcionado à pesquisadora do IEB, mas a devolução não aconteceu.

5 Segundo Marta Rossetti Batista: "Assim como restam poucos dados sobre a vida e as atividades de Anita Malfatti na Alemanha entre I9Io e I9I4, também são escassas as obras da época hoje conhecidas” (BATISTA, 2006, p. 74). 
anotações. Os desenhos configuram esboços, croquis e estudos para obras feitos em sua grande maioria pela própria artista ${ }^{6}$.

No caderno da década de I9Io é possível acompanhar nas páginas iniciais os primeiros passos de Anita Malfatti na viagem de estudos que fez para a Alemanha, custeada por familiares, entre I9I0 e I9I3. Segundo as informações levantadas por Marta Rossetti Batista, a artista procurou uma formação mais tradicional ao chegar à Alemanha: "[Anita] prestou exames em francês, e frequentou por um ano a Academia Imperial de Belas Artes de Berlim, nas aulas de perspectiva, História da Arte e desenho" (BATISTA, 2006, p. 56). Uma parte desses estudos de perspectiva aparece com anotações em alemão nas primeiras páginas desse caderno que possui os relatos da exposição de I9I4 (Figura I).

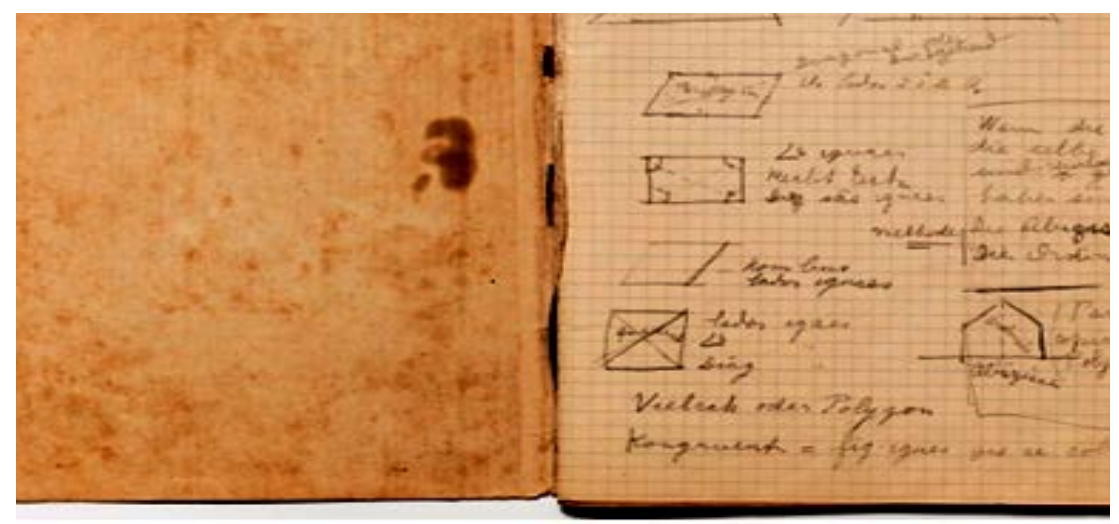

Figura I - Anotações em alemão no caderno que contém os relatos da exposição de I9I4. Arquivo do Instituto de Estudos Brasileiros da Universidade de São Paulo (IEB/USP). Fundo Emilie Chamie. EC-PROJ-AM-ooI

Em um segundo momento desse caderno (Figura 2), no entanto, aparecem as entradas com datas das observações e impressões da artista sobre a sua exposição de I9I4 montada no salão de chá do primeiro andar da loja de departamento Mappin Stores, fundada um ano antes e que era:

[...] dirigida à elite e à classe média emergente, privilegiando os produtos estrangeiros. Sua estratégia de venda e sedução pautava-se na ideologia do preço fixo e visível e no clima de festa permanente que a loja exibia - realçado pelo luxo de sua arquitetura e mercadorias, utilizadas com frequência como elementos decorativos. A exemplo do que

6 Os cadernos da década de I920 armazenam alguns poucos desenhos cuja autoria não é da artista e sim de Victor Brecheret. No período em que Anita Malfatti esteve na França, entre I923 e I928, muitos artistas brasileiros passavam temporadas no país, alguns deles mais próximos à artista, como o caso do escultor. Essa rede de sociabilidade presentificada em seus cadernos de desenho também pode ser conferida em outros documentos de seu arquivo, como na correspondência com Mário de Andrade em que relata seu cotidiano, sua relação com outros artistas brasileiros e a percepção e o juízo acerca de suas produções artísticas. 
ocorria com o comércio e as lojas de departamento parisienses, o público feminino era o principal alvo de atenção. (CINTRÃO, 200I, p. I5-I6).

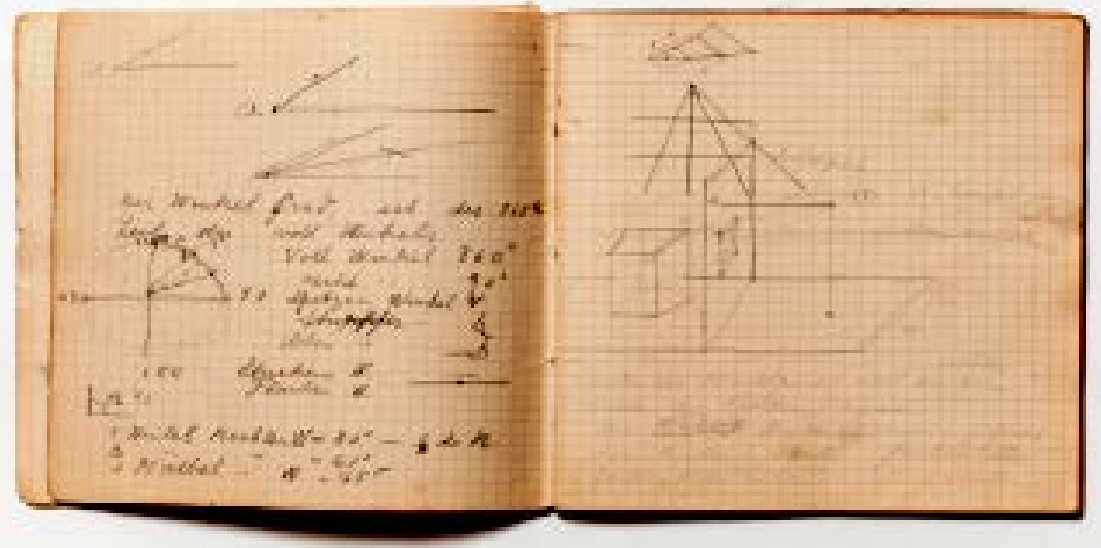

Figura 2 - Estudos de perspectiva e geometria em alemão no começo do caderno com os relatos da exposição de I9I4. Arquivo do IEB/USP. Fundo Emilie Chamie. EC-PROJ-AM-ooI

Muitos aspectos desse espaço expositivo improvisado, característico, segundo Rejane Cintrão, das exposições de trabalhos artísticos nas primeiras décadas do século XX em São Paulo, estão presentes nas observações de Anita e, ainda, em dois registros fotográficos que também estão no arquivo do IEB. Elementos também da montagem do evento e da colaboração de outras pessoas do meio e da própria mãe da pintora, que era também artista, compõem um registro vivo e intenso - e crítico - relacionado tanto à exposição quanto ao meio artístico. Outro aspecto bastante saliente nesse registro é que expor nessas salas "alternativas" obrigava, ainda segundo Cintrão, os artistas a ocuparem condições diversas, como de montadores, produtores, curadores e marchands, entre outras (CINTRÃO, 200I, p. 37), o que é um indício do baixo grau de profissionalização do meio artístico nesse momento.

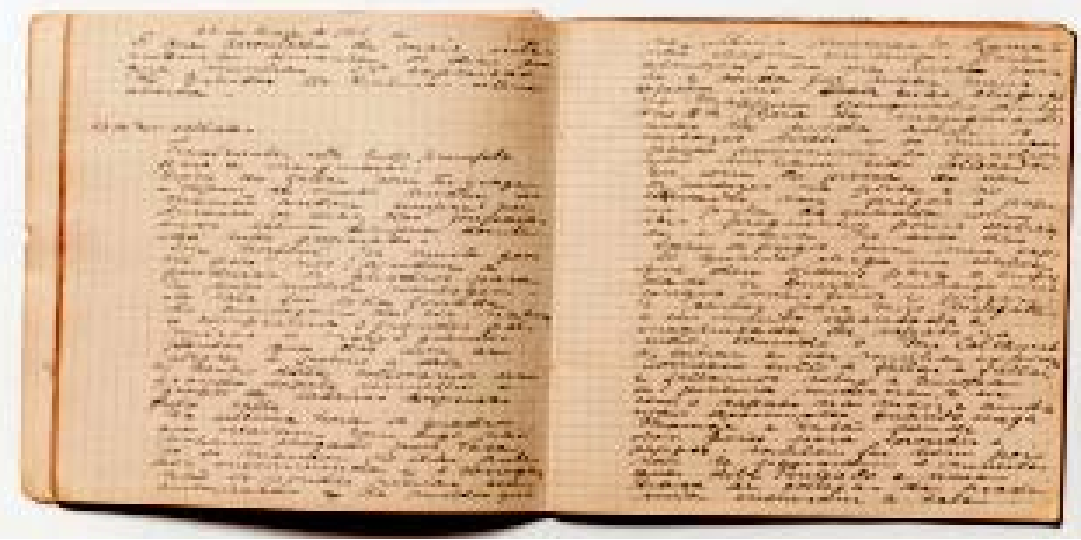

Figura 3 - Arquivo do IEB/USP. Fundo Emilie Chamie. EC-PROJ-AM-ooI 
A artista, ainda, esboça os contornos desse campo em formação e o papel da elite paulista nele. Segundo Tadeu Chiarelli, essa elite soube “- desde o início da Primeira República - confundir-se com o próprio governo estadual, sem nenhum tipo de problema" (CHIARELLI, I995, p. 46), o que, ainda segundo o historiador, não acontecia no Rio de Janeiro, onde existia uma gestão do Estado mais efetiva "através de seus quadros profissionais, sem que a burguesia precisasse colocar à frente de seus eventos elementos de seu grupo" (CHIARELLI, I995, p. 46). Em alguns depoimentos que a artista deixou no diário é possível enxergar esse funcionamento e, também, medir o quanto Anita Malfatti estava de fato envolvida com os principais atores das artes plásticas de São Paulo daquele momento. Entre esses, o mecenas, poeta e senador pelo Partido Republicano Paulista (PRP) Freitas Vale, figura central no campo. São citadas ainda nessas entradas pessoas da imprensa e os principais artistas daquele contexto, entre eles: Oscar Pereira da Silva, Pedro Alexandrino, George Fischer Elpons, William Zadig, Nestor Rangel Pestana, Alfredo Norfini - que colaborou intensamente na montagem do evento -, entre muitos outros. Esse documento do arquivo é central para reconstituir o campo artístico da década de I9ıo em São Paulo.

Já nos cadernos da década seguinte, as anotações são poucas e referem-se à marcação de seu nome na primeira folha dos cadernos, lista de gastos (que revelam, mesmo que timidamente, dados importantes sobre sua rotina, particularmente em Paris) e de materiais, referências às mulheres que lhe serviram de modelo para estudo do nu, alguns dados sobre composições ali armazenadas e poucas menções a endereços.

Esses cadernos de desenho não apresentam datas ou quaisquer indicações que possibilitem afirmar uma intenção da artista em ordená-los, como acontece com o da década de I9Io. Porém, em alguns deles os próprios desenhos, sobretudo os de nu (Figura 4), parecem obedecer a um ordenamento que está associado ao ritmo empregado por ela ao estudo do corpo humano feminino. Também não se distanciam dessa intenção alguns estudos para obras, como o caso da obra Ressurreição de Lázaro, reconhecida por Marta Rossetti Batista como a obra-tese do período em que esteve em Paris (BATISTA, 2006, p. 355). 


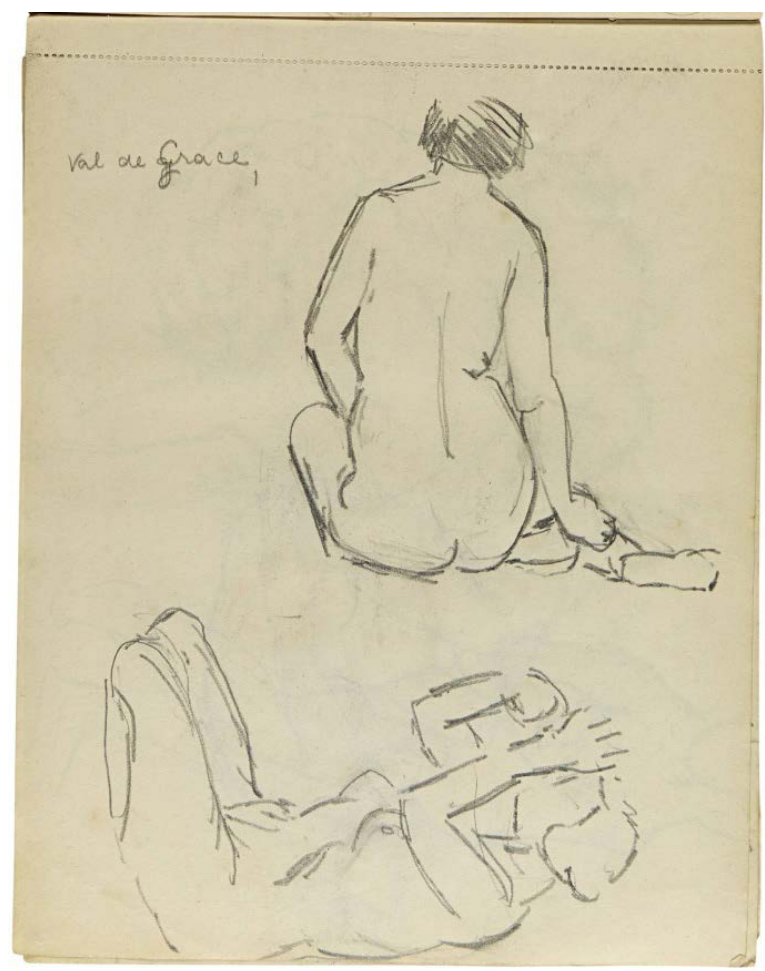

Figura 4-Nu sentado de costas e esboço de nu ajoelhado. Bloco de desenho - sem capa, I924-25c - caderno (desenho), I7 cm x 20,7 cm. Coleção de Artes Visuais - IEB/USP. Coleção Anita Malfatti. CAV-AM-CD-00o6_IGv

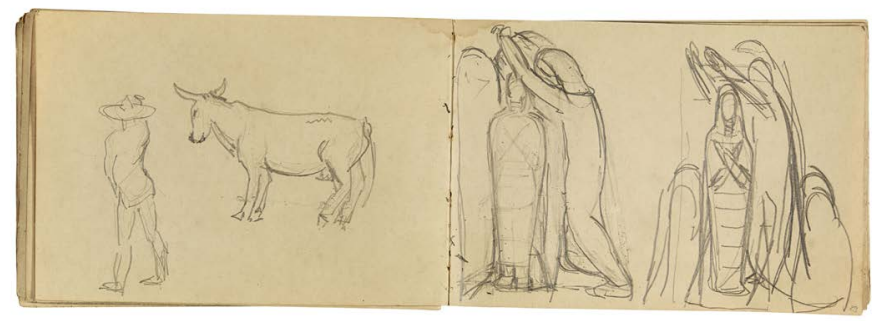

Figura 5 - À esquerda, Esboço: figura masculina e vaca (CAV-AM-CD-0003_28v);

à direita, Estudos para Ressurreição de Lázaro (CAV-AM-CD-0003_29f) .

Caderneta de desenho II - capa acinzentada, I923-24c - caderno, II,3 cm x I6,4 cm. Coleção de Artes Visuais - IEB/USP. Coleção Anita Malfatti

Se o fato de a artista não ter colocado datas nos cadernos traz certa dificuldade para estabelecer os diferentes tempos, contextos e trajetórias, os desenhos, como já mencionado, e as anotações permitem entendê-los no limite das questões mencionadas acima. Como um exemplo mais evidente relacionado a um período datado entre I923 e I928, quando a artista esteve em Paris pelo Pensionato Artístico 
de São Paulo7, existe um conjunto de nove cadernos cujas inscrições, anotações, estudos de nu e de obras remontam de maneira mais imediata à sua fase francesa. Porém, se alguns cadernos acolhem inscrições "em série" que permitem situá-los no tempo e no espaço, outros armazenam apenas desenhos únicos, diferentes entre si, sem indicação sequencial, por isso a dificuldade em vinculá-los a obras já catalogadas e conhecidas da artista.

É possível, no entanto, perceber em alguns deles a presença de desenhos e anotações que remontam a períodos e fases distintas. Isso se deve provavelmente a uma espécie de reutilização dos cadernos, que de alguma forma reforça o fato de cadernos de artistas serem produtos de um contexto íntimo e de um uso rotineiro, tal qual, talvez, uma espécie de diário. Cadernos de artista, em geral, que funcionam como suportes centrais de uma prática de registro corriqueira, estão sempre à mão para registros de vivências (sejam elas breves ou de maior planejamento), ideias e fatos a serem rememorados (GUARALDO, 2006). Se por um lado a possibilidade do registro de algo - percepções e ideias - burlando a fugacidade do tempo (o instante que "voa") parece ser uma das funções mais caras aos cadernos, por outro, a possibilidade de armazená-los para além de um tempo determinado é uma característica que os torna, também, convidativos ao uso.

Essa espécie de "ateliê de bolso" informa aquilo que o artista recolheu do mundo, seu banco particular de imagens, suas reservas poéticas (Maiakóvski). São registros de uma vivência, uma ideia, um fato a ser rememorado. $\mathrm{O}$ artista conhece a fugacidade desses momentos e encontra seu modo de resguardar esses instantes frágeis, porém férteis. Surgem, assim, [semelhantes aos] os diários. 'GUARALDO, 2006, p. 80).

À luz desse sentido de intimidade, rotina de registros e rememoração, os cadernos de artistas podem, portanto, ser vistos como diários, ainda que muito singulares. É o caso do conjunto de cadernos de desenhos que testemunham a passagem de Anita Malfatti por Paris, como já mencionado, na década de I920, que podem ser compreendidos como cadernos-diários, mesmo que não estejam presentes características distintivas fundamentais, como os vestígios de datas e a constituição de uma narrativa linear (VALIN, 20I5). À maneira de diários, portanto, testemunham a intimidade de sua vida, seu itinerário de criação em Paris. Ao inscrever uma lista de gastos em um dos cadernos de desenho (Figura 6), por exemplo, concede-nos informações importantes sobre seu itinerário de formação, que, para além de outros espaços que tenha frequentado, informa, particularmente, sobre sua passagem pela Académie de la Grand Chaumière. Essa mesma lista também deflagra como era

7 O Pensionato Artístico de São Paulo, regulamentado em abril de I9I2 pelo decreto n. 2.234, visava instrumentalizar o desenvolvimento artístico carente de cursos superiores no estado de São Paulo, fomentando bolsas de estudos a jovens paulistas que demonstrassem decidida vocação artística paras as belas-artes nos principais centros artísticos da Europa (cf. CAMARGOS, 20II). 


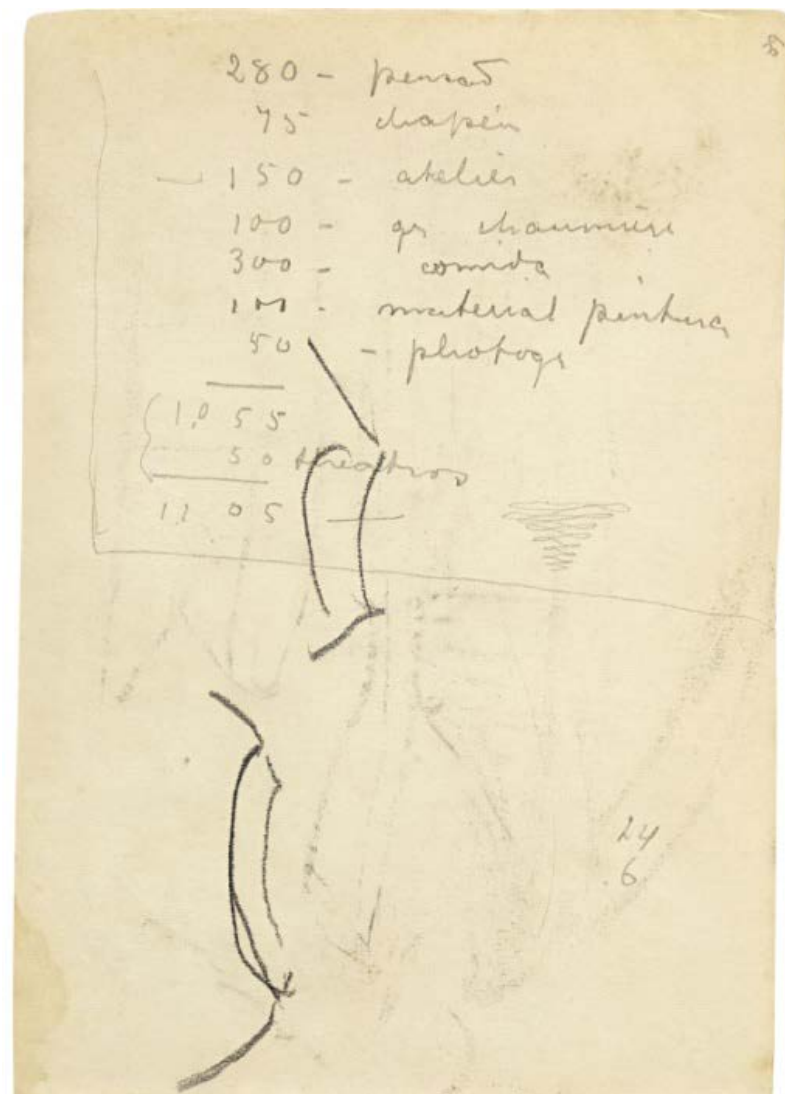

Figura 6 - Contas. Na imagem vê-se a rubrica dos gastos efetuados pela artista, dentre eles Ioo (francos) empregues na Académie de la Grande Chaumiére. Caderneta de desenho II, I9I8/24c - caderno (desenho), II,3 cm x I6,4 cm. Coleção de Artes Visuais - IEB/USP. Coleção Anita Malfatti. CAV-AM-CD-0003_39f

8 O valor mensal da bolsa instituída pelo Pensionato Artístico de São Paulo ficava em torno de 4:000\$ooo quatro contos de réis - ao longo de três anos, com possibilidade de extensão desse período, como foi o caso de muitos artistas, inclusive de Anita Malfatti. "Com a bolsa os pensionistas deveriam pagar o curso nas escolas ou as aulas particulares, conforme o caso, além de arcar com as despesas de moradia, transporte, lazer, material de estudos e todo o restante necessário aos gastos diários. Não raro, os recursos chegavam com atraso ou terminavam antes do mês, levando os artistas a recorrerem a Freitas Valle ou até ao presidente do Estado por meio de abaixo-assinados" (CAMARGOS, 20II, p. 65). Diferentemente das outras viagens que fizera, as quais foram financiadas por sua família, em Paris Anita Malfatti vivia como uma pensionista do estado, o que implicava viver com uma bolsa mensal (que por muitas vezes era disponibilizada com atraso) que não lhe permitia fugir de um orçamento justo e regulado. 
Quanto aos nus femininos esboçados em quantidade, estes revelam características importantes acerca de sua "escrita" gráfica e de seu método9, ao passo que, concomitantemente, também corroboram para sua escrita de si. E ao imprimir essa escrita a partir de notações gráficas e escriturais em seus cadernos e, consequentemente, ao acumulá-las e guardá-las objetivando um repositório sempre à mão de rememoração, Anita Malfatti forja uma imagem de si em consonância com a crítica, nacional e internacional: uma artista que, para além de pintora, foi uma aclamada desenhista.

Dentre esses conjuntos de documentos nomeados de "cadernos", existem no Arquivo do IEB/USP dois classificados como "cadernos de recortes" que apresentam características, interesses e objetivos diferentes quando comparados aos de desenho. São classificados dessa forma por terem como técnica de registro dominante o recorte e a colagem de artigos de jornais e periódicos, embora essa prática, muitas vezes, conviva lado a lado com diversos tipos de anotações ali expressas pela artista.

O primeiro deles é uma brochura de dimensões 32,6 x 22,5 cm, com capa dura em tecido na cor preta ${ }^{\mathrm{IO}}$. As 50 folhas que o compõem encontram-se numeradas e amareladas pelo tempo. Quanto ao conteúdo, acolhe, além de recortes, um conjunto de anotações importantes para a compreensão da artista no campo intelectual e artístico paulista nas primeiras três décadas do século XX. As primeiras páginas fazem referência a uma lista datilografada, sob o título de "Exposição de Pintura Moderna Annita Malfatti”, contendo os nomes das obras expostas na Individual da artista de I9I7 e seus respectivos valores.

$\mathrm{Na}$ sequência encontra-se a lista de assinaturas da mesma exposição. Nela aparecem familiares, amigos e nomes importantes do meio intelectual e artístico de São Paulo, com destaque para aqueles que viriam a ser seus francos defensores e apoiadores: Oswald de Andrade e Mário de Andrade - este último marcou presença mais de uma vez ao longo do tempo em que a exposição esteve aberta. Ao final da lista há uma anotação da artista que contabiliza o total de visitantes que passaram na exposição, I.250 pessoas.

Logo após surge o primeiro bloco de recortes de jornais do caderno, que tratam de artigos publicados em jornais e revistas, como Correio Paulistano, A Vida Moderna, Jornal do Commercio, Revista Feminina e O Estado de S. Paulo, para citar apenas alguns. Os recortes destacados e colados pela artista, em sua maioria, fazem alusão à sua emblemática exposição de pintura moderna de I9I7. Aparecem colados ou afixados na parte superior com grampos e organizados de tal maneira que é possível perceber uma tentativa de estabelecer uma cronologia - especulação possível, pois abaixo da maioria dos recortes encontram-se anotações manuscritas, espécies de legendas com

9 "Um olhar mais atento sobre esses cadernos ainda destaca outro dado sobre a prática do desenho por Anita: a presença de um método. As marcas de lápis, algumas mais fracas ou apagadas, revelam seu método peculiar de desenhar, o qual consiste, primeiramente, em cuidar de esboçar de forma rápida o corpo da modelo para, em seguida, defini-lo com uma linha precisa e contínua que aproxima seu traçado dos desenhos clássicos, [que] segundo Winckelmann, [são] portadores de uma nobre simplicidade e uma grandeza serena” (VALIN, 20I6, p. 250).

Io Cf. Arquivo IEB/USP, Fundo Anita Malfatti, código do documento: AM-05.02.0000. 
informações que tratam das datas das publicações, nome do veículo e, em alguns, o título do artigo.

Em seguida, duas outras listas de assinaturas aparecem, " $3^{a}$ exposição: I8 de novembro de I920" e " 4 " exposição - 24 de fevereiro de I92I", respectivamente. A primeira lista, que se refere à exposição aberta entre novembro e dezembro de I920, atesta a presença de artistas e escritores, com destaque para Mário de Andrade, Victor Brecheret, Georg (Jorge) F. Elpons, Alfredo Volpi, Monteiro Lobato, Gastão e Bertha Worms e Pedro Alexandrino, somando-se aos aproximadamente 570 visitantes. Alguns desses nomes assinaram mais de uma vez, indicando que fizeram mais de uma visita à exposição. A segunda lista, por sua vez, traz poucas assinaturas, aproximadamente I05 nomes.

O segundo caderno, verde com lombada verde-escura (Figura 7), com 23,8 $\mathrm{cm} \times 16,5$, possui 99 páginas não numeradas. No verso da primeira guarda há o carimbo "Casa Espindola/Rua Libero Badaró, 48 - S. Paulo", com numeração a lápis “I202/ 4500”. As informações que o caderno abriga correspondem à lista de assinaturas de sua individual ocorrida em novembro de 1935 e matérias extraídas de publicações veiculadas em jornais e periódicos no Brasil e no exterior, especificamente na França.
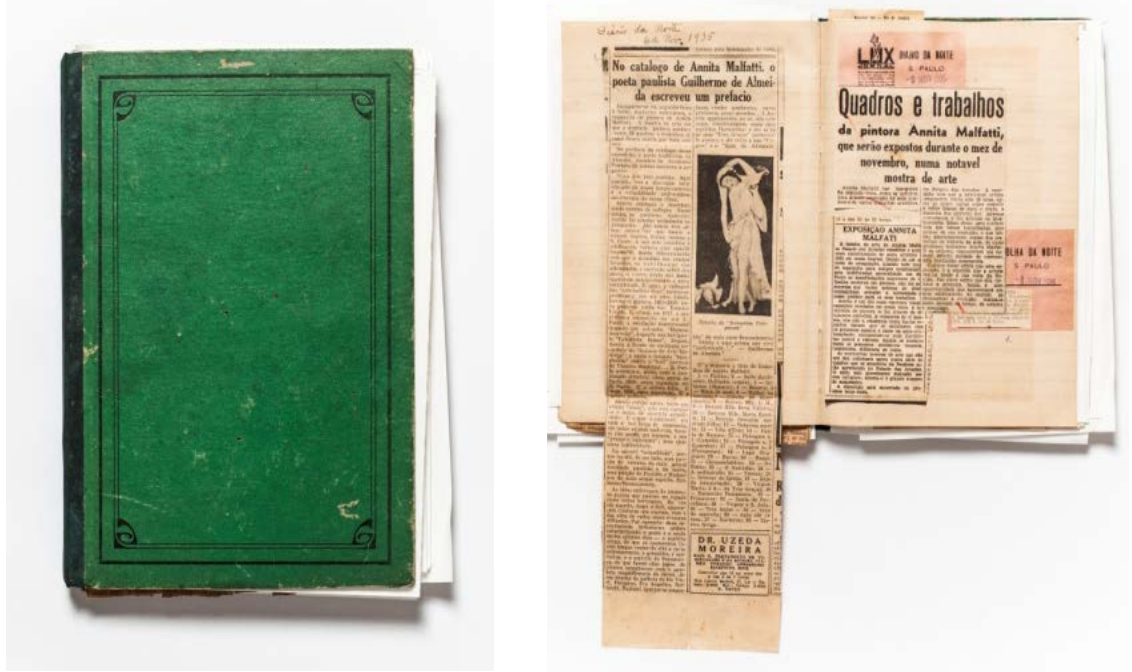

Figura 7-Caderno com recortes de jornais, capa verde. Arquivo do Instituto de Estudos Brasileiros da USP, Fundo Anita Malfatti, código de referência: AM-05.09.000

Diferentemente dos cadernos de desenho, cujas funções estão atreladas ao registro e armazenamento de percepções, ideias, lembretes e reflexões sobre a vida e a arte (pensando em cadernos de artistas), conferindo-lhes características como flexibilidade e espontaneidade, os cadernos de recortes resultam de

II Cf. Arquivo IEB/USP, Fundo Anita Malfatti, código do documento: AM-05.09.0000. 
uma ação intencional, contraditoriamente não espontânea, que diz respeito ao armazenamento de informações selecionadas por alguém e que cumpre determinada função na vida e no processo de criação dos seus produtores, no caso a artista.

É importante ressaltar que o hábito de recortar e colar, de acordo com José Francisco Guelfi Campos, sugere uma prática social recorrente que remonta a uma ação de acumulação que muitas vezes foi estimulada desde a infância, ligada ao lúdico e ao lazer e que na vida adulta não deixou de existir, assumindo significados e funcionalidades bastante diferentes (CAMPOS, 20I7). Esta parece ser uma explicação coerente para o fato de

[...] recortes de jornal serem muito comuns e volumosos em arquivos pessoais, [e sua presença] não se deve ao acaso: assim como os demais documentos [ali presentes], [...] são passíveis de contextualização em função de eventos, atividades ou áreas de interesse de quem os acumulou. (CAMPOS, 20I7).

Anita Malfatti em seus "cadernos de recortes" prioriza, ao que parece, sua trajetória profissional procurando estabelecer por meio dos recortes que seleciona momentos-chave da sua carreira, construindo e preservando uma imagem de si de natureza pública, ou seja, de uma artista moderna a seu modo, algo diferente, como dito, dos cadernos de desenho que são parte efetiva do seu processo de criação.

Assim, arquivos pessoais se constituem como conjuntos de documentos que instrumentalizam e representam, a título de prova ou referência, as atividades de determinado indivíduo ao longo de sua vida ${ }^{\mathrm{I} 2}$, o que vale, claro, para os arquivos de artistas. Materializado por cadernos - como os discutidos aqui - e também por cartas, manuscritos, datilográficos, fotografias, matrizes de gravura, cartões de visita, documentos de identificação pessoal, entre outros, o arquivo pessoal de Anita Malfatti, com maior ou menor intensidade e com alguns pontos que requerem um olhar e uma discussão mais detida, reúne essas características apresentadas anteriormente e outras a serem (re)descobertas. Percorrer o arquivo da artista é uma maneira efetiva de procurar traços de uma Anita que ainda precisa ser revelada.

I2 Essa definição foi dada pela professora doutora Ana Maria de Camargo (FFLCH/USP), durante a oficina “Arquivos de artistas”, incluída na programação do II Encontro de Arquivos Pessoais: Experiências, Reflexões e Perspectivas, promovido pela Associação de Arquivistas de São Paulo em dezembro de $20 I 7$. 


\section{SOBRE OS AUTORES}

ROBERTA VALIN é mestre pelo Instituto de Estudos Brasileiros da Universidade de São Paulo (IEB/USP) e docente da Faculdade de Artes da Universidade Federal do Amazonas (Faartes/UFAM). E-mail: robertaparedesvalin@gmail.com

CARLOS PIRES é pós-doutorando no IEB/USP, professor do Instituto Superior de Ensino Vera Cruz, pesquisador no Instituto de Estudos Brasileiros (IEB/ USP) e autor dos livros Apuros modernos: o jovem João Cabral de Melo Neto (20I6) e Frio tropical: tropicalismo e canção popular (20I7).

E-mail: pirescarlos@gmail.com

\section{REFERÊNCIAS}

IEB - Instituto de Estudos Brasileiros. Catálogo Eletrônico. Arquivo. Disponível em: <http://200.I44.255.59/ catalogo_eletronico/consultaAcervosArquivo.asp >. Acesso em: 30 jun. 2018.

.Catálogo Eletrônico. Coleção de Artes Visuais. Disponível em: <http://200.I44.255.59/catalogo_eletronico/consultaAcervosCAV.asp >. Acesso em: 30 jun. 2018.

BATISTA, Marta Rossetti. Anita Malfatti no tempo e no espaço. São Paulo: IBM Brasil, I985.

. Anita Malfatti no tempo e no espaço. São Paulo: Editora 34/Edusp, 2006.

CAMARGOS, M. Entre a vanguarda e a tradição. Os artistas brasileiros na Europa (I9I2-I930). São Paulo: Alameda, 20II.

CAMPOS, J. F. G. Tipologia documental em arquivos pessoais: entre a Arquivística e a Diplomática. In: GARCÍA, Noelia; MELLO E SILVA, Maria Celina Soares (Coord.). Archivos personales: experiencias de organización y gestión, I. Livro digital. Córdoba: Redes, 20I7, p. 52-7I.

CHIARELLI, Tadeu. Um Jeca nos vernissages. São Paulo: Edusp, I995.

CINTRÃO, R. L. As salas de exposição em São Paulo no início do século: da Pinacoteca à Casa Modernista (I905-I930). Dissertação (Mestrado em Artes Plásticas). Escola de Comunicações e Artes, Universidade de São Paulo, São Paulo, 200I.

GUARALDO, L. O território do caderno de criação. Manuscrítica - Revista de Crítica Genética, Vitória, n. I4, dez., 2006, p. 80-87.

SIMIONI, A. P. C. Do centro às margens - uma revisão necessária. Moderno MAM Extra - Anita Malfatti - Ioo anos de arte moderna. São Paulo: Ministério da Cultura/Museu de Arte Moderna, ano 9, n. 6, fev.-abr. 20I7, p. II-I4.

VALIN, R. P.Cadernos-diários de Anita Malfatti-uma trajetória desenhada em Paris. I23p. Dissertação (Mestrado em Culturas e Identidades Brasileiras). Instituto de Estudos Brasileiros, Universidade de São Paulo, 2015.

VALIN, Roberta Paredes. Os cadernos de desenho de Anita Malfatti. Um diário de criação à revelia e índices de um projeto pictórico em Paris. Revista do Instituto de Estudos Brasileiros, n. 63, abr. 20I6, p. 242-257. 